\title{
Matching Education and Training to Employment: Practical Problems and Theoretical Solutions - Or the Other Way Round?
}

\section{Lorenz Lassnigg}

Institute for Advanced Studies (IHS). Department of Sociology

lassnigg@ihs.ac.at

\begin{abstract}
This article aims to contrast various theoretical approaches on the coordination between education-and-training and employment with a set of practical solutions and policies. Adopting a broad view, we hope to discover several paths that allow us to illuminate solutions to practical as well as theoretical problems, or at least to outline trajectories for further analysis. The practical solutions and policies discussed focus on the Austrian experience.
\end{abstract}

Key words: education-and-training and employment coordination; matching theories; Austrian practices and policies.

Resumen. Adecuar la educación y la formación al empleo: problemas prácticos y soluciones teóricas -o lo contrario?

Este artículo contrasta los diferentes planteamientos teóricos sobre la coordinación entre el formación/educación y empleo con sus aplicaciones prácticas y políticas. Desde un enfoque amplio que espera encontrar algunos caminos que nos faciliten encontrar solución tanto a los problemas prácticos como teóricos, o, por lo menos, para esbozar algunos caminos que nos permitan avanzar en el razonamiento y análisis acerca de esta coordinación. Las soluciones prácticas y políticas presentadas se basan en la experiencia austríaca.

Palabras clave: coordinación entre formación/educación y empleo; teorías de la adecuación; prácticas y políticas en Austria.

\section{Summary}

1. Introduction

2. The Scope of the Problem Reflected by Theories in Contrast to Proposed Practical Solutions

3. The Contested Role of Policy: Demands vs. Potentials?
4. The Austrian Experience of Matching and Coordination

5. Conclusions: Lessons and Proposals for Further Development

Literature 


\section{Introduction}

This article reflects on the coordination or matching between education-andtraining (ET) and employment by confronting various theoretical approaches with a set of practical solutions. This analysis focuses on the Austrian national system in a comparative perspective. Throughout this article, matching is used in a general sense to include different layers of matching, ranging from the structural level through the meso-institutional level to the individual level. This general sense of matching does not imply a rigid 1:1 relation between ET and employment, but a more contingent "reasonable" match. We attempt to bring together at least three different worlds, which are commonly debated separately and each of which includes many contradictory views and tricky questions: theories (section 2), practice (section 3) and policy (section 4). We take a broad view and are aware the picture will remain sketchy; however, we expect to discover several paths that allow us to illuminate solutions to practical as well as theoretical problems, or at least to outline trajectories for further analysis.

\section{The Scope of the Problem Reflected by Theories in Contrast to Proposed Practical Solutions}

\subsection{Theoretical approaches about the changing relationship of ET and employment}

The problem can be set out by confronting the deep divide between practical discourses and expectations and theoretical reasoning concerning the relation between ET and employment. Today, thousands of people in Europe and millions of people throughout the world undergo training and acquire qualifications in the expectation of finding a job, or at least improve the likelihood of finding a job. Many ET providers confirm this expectation to be reasonable. ${ }^{1}$ However, several strands of research and theory contradict these expectations, and instead for various reasons argue in favour of a process of "decoupling" ET from employment. The main paradigms that inform us about the problems involved in coordinating ET and employment at an aggregate theoretical level are systems theory, innovation theory, modernisation theory, economic market theory, and theories of learning and competence.

\subsubsection{Systems theory}

Systems theory holds that each subsystem of society emerges and functions by following its own logic ("autopoiesis"), and no perspective is able to coordinate across different systems (Luhmann and Schorr, 2000). In this view, the political system is incapable of acting as a coordinator because it also emerges and functions according to its own logic at the same level as the other subsystems. The

1. The OECD and EU19 average of enrolment in vocational programmes at upper secondary level is between 45\% and 50\% in 2004 and 2005 (EAG, 2007, Table C1.1., EAG, 2006, Table C2.5). 
market as a mechanism that is genuinely related to the economy is also discarded as a coordination mechanism for ET. Only coupling mechanisms between subsystems that are in autopoiesis will emerge, but which coupling mechanisms may be at work between education and employment so far remains unclear. Two candidate mechanisms are: selection and individual search for a stepwise career during the life course (biography).

\subsubsection{Evolutionary innovation theory}

Evolutionary innovation theory, which is based on an institutional paradigm, outlines a historical argument for the view that the current ET systems, in particular the vocational education-and-training (VET) sector, emerged in the industrial society. Because of institutional inertia these systems are today still representative of that era, thus creating expectations that no longer hold in the current service society, and particularly in the knowledge or learning society (Nieuwenhuis 2004, Lundvall and Borrás 1998). This view receives support from new estimations of models based on different strands of "new growth theory", which indicate that a move towards the technology frontier - and, accordingly, the positive effects for economic growth resulting from ET - are produced by higher education (HE) rather than by upper secondary VET (EUDG Employment, Social Affairs and Equal Opportunities, 2006).

\subsubsection{Theories of modernisation and institutional change and inertia}

Theories of institutional change and the increase of "individualisation" in the neo-liberal movement predict a radical decline of the core traditional structures. This particularly concerns the traditional occupations and their associated identities that served as the main building block of VET (Beck, 1992: ch. 5). However, it is less clear what the functional equivalent for those eroding structures is. A stronger personal identity and competences to cope with mobility, change, and complexity are candidates, but some commentators argue that men and women would be too strained by such changes (Sennett, 1998). The theorem of the institutionalisation of VET and its structures in the industrial era fits neatly into this theoretical strand, as do the ideas and research in organisation theory indicating the fundamental "reform resistance" of educational organisations (Weick, 1976).

\subsubsection{Labour market theory}

Labour market theory has always held conflicting views about the relation between ET and employment. The concepts of productivity and wage setting are situated at the centre of this relationship. The extreme market approaches have typically regarded ET as an external and indirect factor influencing productivity and the reservation wage. Questions about causality have been shifted to the economics of the education market, where the contradicting expectations about the causal effects of training - increase of productivity versus screening or signalling - have never been resolved (Blaug, 1976). Segmentation theories have internalised occupational structures in the form of supply monopo- 
lies or informational assets by creating a circumscribed commodity or "trade mark" (occupational labour markets). On the enterprise side, internal markets were expected to undermine occupational markets by creating informal links between employees and enterprises that limited employee mobility to move between enterprises. Segmentation theory further holds that pure economic mechanisms only remain in place in relation to unqualified or semi-skilled "everybody" markets (Sengenberger, 1987). However, the institutional changes succeeding neoliberal deregulation have in fact severely undermined the structuration predicted by segmentation theory, which can also be regarded as deriving from traditional Fordist industrial structures and bureaucratic industrial organisation. Even in economic research about mismatch in the labour market, the occupational structure of VET does not play a main role: the core theorems continue to be "fluidity" and "mobility" rather than "occupational attachment as an asset". The standard economic measures of mismatch still refer to crude structural aspects of overall labour market supply and demand on the labour market, instead of the aspects of skills content captured by the notion of mismatch concerning VET specialisations (Lassnigg, 2005; EU-DG Employment and Social Affairs, 2002).

\subsubsection{Theories of learning and competences}

Theories of learning and competences also tend to value generalised assets (e.g., the classification of personal, social and generalised instrumental competences) over the occupational core of traditional VET (Berryman and Bailey, 1992). In this context, a fierce battle takes place between an "old" and a "new" paradigm, which primarily ensues at the ideological plane. This is because of the broad scope of the beliefs involved, as well as a lack of rigorous empirical indicators for deciding between the alternatives, makes it difficult for the two paradigms to compete at the plane of science or empirical analysis. On the one hand, we find the traditional view of the acquisition of skills (and associated identities) by practical learning-by-doing, and the formation of occupational competences at an early age (following the paradigm of craft or techniques in arts), which supports a strong focus on upper secondary VET and attaches only a low, supplementary value to HE. On the other hand, there exists a new view, strongly grounded in a constructivist paradigm of learning, that emphasises new generalised competences - in particular self-competence and learning capacity as sources of flexibility and adaptability. This new paradigm regards the competences acquired in HE, in particular the access to and understanding of knowledge creation, as the main assets of ET systems. What is at stake in the battle between these competing paradigms is the expectation about the population's capacity to acquire particular competences. "Traditionalists" take a pessimistic and limited view in which ET provision becomes rather a "stretching" device for individuals. The new paradigm, by contrast, adopts an optimistic and expansionary view of the potentials of individuals with ET provision rather being an endeavour toof "ration" those potentials in order to limit the expansion of academic and higher education. 


\subsection{Practical solutions and their limitations}

Taking the theories and approaches sketched above together, we observe a complex relationship between ET and employment; a complexity that is not adequately reflected in approaches that try to find practical possibilities of matching or coordination between the two societal fields or subsystems of ET and employment. These practical approaches observe a mere technical problem as opposed to a fundamental problem of social structures and conflicting expectations. In the next section, we summarise these practical approaches and extract their underlying assumptions about the relation between ET and employment.

\subsubsection{Forecasting and planning}

The leading traditional approach for resolving the relation between ET and employment has been the forecasting and planning approach originating in the 1960s. This approach is outdated, and even the slightest indirect reference to its ideas is discredited. Nevertheless, we have to contend that the basic ideas of this approach are still operating in the background of many of the discourses about ET and employment. These basic assumptions are: (1) ET systems do not provide qualifications for the present, but for an as-yet-unspecified period in the future; (2) because of economic dynamics and structural change we expect future demand for qualifications to be different from the present one; (3) the future demand for qualifications can be forecast by using statistical or economic modelling; (4) the state, as the main provider of qualifications, is responsible for the planning of ET supply following the forecasts.

Although the planning approach is highly discredited, forecasting remains very much alive. Most countries engage in forecasting in one way or another. In addition, the EU has recently provided forecasts of the demand for qualifications for all member states (Neugart and Schömann, 2002; Zukersteinova and Strietska-Ilina, 2007; Wilson, 2007). But how can we resolve the contradiction of what to do with forecasts if planning is not possible?

The most simple and convincing response is that every provision system of occupation-related qualifications must accept that it is producing qualifications for the future; after all, to produce qualifications only for the moment alone would not justify its costs. Providers necessarily rely on assumptions or ideas about the future. Those assumptions, in turn, can be implicit and informal or explicit and formal: the latter are obtained through forecasting.

However, the question remains what forecasting procedures that are not related to planning really add to the solution of the matching problem? We can identify different functions for different players. First, forecasting generates income for the forecasters; it also generates a good reputation, provided the results are within a reasonable range of credibility and validity. Second, for the decision makers and providers, forecasting allows them to compare their own expectations to systematic challenges. Third, forecasting offers crude orientation points for the demand for education and its supporting agents (e.g., information and counselling institutions). 
In sum, if we separate the forecasting procedures from the traditional notion of planning, and if we also leave aside the expectation of telling "the truth", forecasting provides useful material for the relevant actors to learn about the development of the relationship between ET supply and demand. Necessary conditions for this usage include: meaningful categories, regular exercises, and communication structures among the actors that allow effective processing of the knowledge provided, no matter how limited.

The main problems with these procedures are twofold. On the one hand, actors still approach forecasting from within the planning paradigm. On the other hand, both providers and users of forecasting are inclined to overstate the truth of the resulting figures instead of being fully aware of their dependence on to the assumptions of the forecast. The danger of misunderstanding is particularly salient in forecasting projects with low regularity and poor communication that feature "big shot" procedures. It is difficult to ascertain the extent of this danger in practice, given the stereotypical negative reaction to the planning paradigm and the "myth of truth" attached to seemingly clear numbers on the other. Nevertheless, how can forecasters and commissioning bodies remain motivated to expend effort and resources on such a demanding enterprise, given the amount of relativity and fallibility implied?

The underlying assumption of the planning approach is that matching and coordination cannot function on the basis of self-organisation, or on the basis of emergent processes, and needs to be provided for by a policy process. This implies three requirements: to produce the required information and knowledge, to make the right decisions, and to bring the different actors to the required actions. The third condition in particular is hard to fulfil in marketbased economies and societies; and this is where the market has stepped in.

\subsubsection{Deregulation and marketisation}

Another response to the coordination problem between ET and employment, expressed by the human capital approach, has been to call for a market mechanism. This approach proposes to shift the matching problem from the policy level to the rationality and decisions of individual actors, instead of relying on planners. However, serious doubt remains whether the market is able to perform this coordinating function independently (Booth and Snower, 1996). The unregulated market seems to fail in particular in the area of initial VET for young people; in HE, and in continuing ET, markets might function effectively to some degree, but even in these areas advocates of the market propose strong measures to correct for undesirable incentives and inequity (Barr, 2001, Jacobs and van der Ploeg, 2005). In fact, concerning upper secondary VET, the market approach has largely remained an ideal rather than a practical reality, thus it has never been possible to conduct a genuine reality test of market coordination in this area.

In the area of upper secondary VET at least two problems limit the applicability of the market. The first problem is the early age at which vocational decisions are to be taken, typically at 14 to 16 years old. Since young people 
are not of full age and can only partly be held responsible for their decisions, parents often play a large role in these choices. However, if others partake to such an extent in a critical decision about one's future life, the assumption of rational self-interest is not fulfilled. Relatedly, the second problem concerns the weight of the decision pertaining to the length of the programmes and the expectations about their impact. A basic assumption of traditional VET is that young people must process a comprehensive package, providing a large starting capital to its owner. However, it has been shown that the market approach in ET involves the simultaneous coordination of two markets: the education market and the labour market. The dynamics of the labour market is different from the dynamics of the education market, both in terms of time and in terms of rationality (Grubb, 2002), with the length of education programmes resulting in a time-discounting factor such that current decisions must always be based on future expectations. A paradox now emerges where forecasting through formal modelling is considered impossible, yet forecasting by individuals is considered necessary for them to make rational choices. We might see the main difference in different distributions of errors and in different distributions of responsibilities for them.

Consequently, the market approach includes the "de-packaging" of the initial programmes, typically through modularisation, which also undermines the basic logic of occupational monopolies. Thus, the market approach cannot really offer a solution for the matching or coordination problem, as it objectively destroys what should be coordinated. We can observe these problems in the case of the UK approach to VET, where several qualification schemes have contributed to higher numbers of qualifications and resulting information problems in comparison with occupational systems (Hayward, 2004). The market solution is consistent with those theoretical approaches that indicate a shift towards fully tertiarising VET and abandoning upper secondary VET. This implies advocates of VET must be considered enemies of the market approach (Rauner, 2008).

\subsubsection{Supply-oriented professional ideals of VET}

This approach can be labeled "educational". It relies on conceptions from different occupational fields about which competences are required for professional work and how occupational identities can be built. One element constituting these requirements is the change and development within the occupation or profession, the other is filtering out of what is judged and expected as being constitutive and sustainable in the field. In this approach the emphasis lies mainly on the qualitative aspects of ET, and the mechanisms for assessing quantity and deciding about access and provision might be structured differently among the actors in different ET systems or institutions. Decisions about financing and provision are taken on the supply side of the ET market, while the demand side takes decisions about access and enrolment. Access to the programmes might be organised by different degrees of marketisation, including various mixes of costs and benefits. Typically, we find full-time schooling 
programmes that are often publicly financed, with students mainly incurring opportunity costs. In those cases, the market operates partially and indirectly: decisions about the provision of such programmes are taken institutionally, and the market is involved only in the choices of programmes by students. ${ }^{2}$ Some VET systems also provide enterprise-based apprenticeship programmes, which involve some sharing of costs and benefits between students, enterprises and the public. Since schools are institutionally separated from occupational processes, the problem of how to provide opportunities for practical learning that are in line with rapid changes in working life arises.

There exist two contradictory perspectives on the relationship between the learning environment and working life. On the one hand, the reconstruction of the occupational learning environment at school is considered expensive and difficult to adapt continuously (Middleton; Ziderman and van Adams, 1993: ch. 2). On the other hand, reconstruction of the learning environment at school is considered to somehow provide "the essence" of what is required in an occupational field (Heikkinen, 1997). Of course, enterprises providing apprenticeship have other important functions besides training. Small enterprises in particular typically endorse a wide range of motives for a training decision, and support the existence of different learning environments. While the learning environment might be realistic to some degree, a problem of control nevertheless arises concerning whether the conditions and learning outcomes are sustainable over time.

Overall, the supply-oriented approach entails two key coordination problems: constructing a reasonable distribution of training programmes supply profiles, and constructing an adequate supply profile within occupational specialisations. These two aspects have to be managed simultaneously in a single VET system. However, the supply-oriented approach is fundamentally biased towards the second dimension at the expense of the first: it gives priority to the matching within specialisations. At this point, the argument from inertia comes into play: VET has been created in times of greater stability to reinforce stable occupational profiles by guiding students to master a certain occupation. Advocates, providers, and experts in the system too are geared to a specific occupation or profession, and consequently they struggle to institutionalise the field in a professionalisation process.

Traditionally, VET has had a strong relation to self-employment, which reinforces the attachment to a certain occupational field, and often has related training to requirements or barriers of market access (i.e., the credentials are a condition for running a business, and at the same time the access to training is rationed). As far as employer-employee relations are concerned, the principle of monopolisation of occupational fields entails a conflict of interests: employees favour rationing access in order to drive up wages,

2. How far they empirically take into account the opportunity costs assumed by human capital theory remains disputed. At this point, the tricky questions of empirical rational choice behaviour enter the scene. 
whereas employers are interested in creating an oversupply to restrain wage dynamics.

Looking at the first dimension of coordination - the matching of a structure across specialisations - the logic of the supply-driven system implies a perspective in which structural coordination will not be advocated, new areas will not have an institutional base, and old areas will constantly struggle about the demarcations between each other instead of addressing new fields.

Similarly to the forecasting approach, the supply-oriented approach is likely to be biased towards "overstated realism", in which the actors driving the system (the "insiders") are inclined to emphasise their local practical knowledge as a truth without sufficiently considering its character as a constructed reality routed in the institutionalisation of the existing occupational structure.

\subsubsection{A new learning system through lifelong learning and continuing and further ET} From the late 1980s onwards, when the economy temporarily recovered from the shocks and the stagflation period of the 1970s and early 1980s, ET demand reappeared on the political agenda with a strong focus on the increasing pace of change in employment and the economy more generally. After a period of temporary revival of "vocationalism" and OECD attention to VET through VOTECH studies (OECD, 1989), initial ET was increasingly regarded as no longer able to provide for the range of new demands for skills, competences and qualifications. Instead, lifetime ET has started its revival as the new dominant paradigm and, in its first period during the 1970s, roughly expanded the logic of initial ET to adult and continuing ET. ${ }^{3}$ However, in its second period, the upcoming lifelong learning (LLL) paradigm took a strongly individualistic view of the ET market (Lassnigg et al., 2007).

Subsequently, this development has been reinforced by new concepts such as the information society and the knowledge-based economy, which were at the core of the EU Lisbon summit in 2000. Concerns with change and innovation increasingly emerged as the driving force of society and the economy, and the new paradigm of lifelong learning has put the traditional continuum of ET into question by calling for a new distribution of initial and continuing ET.

There are at least two critical dimensions to this development. The first concerns the basic assumption of this new paradigm that learning occurs not only in formal ET environments. A substantial part of the acquisition of skills and competences take place in everyday life environments, particularly in the workplace. However, these competences are typically not transformed into documented and transferable qualifications. The more this is the case, and the more this undocumented component contributes to the supply of competences, the less valid information formal qualifications contribute to the totality of competences transacted in employment and the labour market (Planas et al., 2002). To rely on information about formal qualifications is

3. Compare the concepts of education permanente by UNESCO, and recurrent education by the OECD. 
clearly misleading when informal elements make up a substantial part of occupational competences. This has important consequences for forecasting procedures, which build on formal qualifications and are captured to some extent by the supply-oriented approach, if experts and providers are really involved in the practical operations at the employment side. The market approach on the ET side might cover this component by supporting the informal acquisition of skills and competences through the provision of complementary programmes.

The second dimension of the LLL paradigm concerns the frequently advocated shift of mixes between different components of competences. There are different expressions of those components: general or specific competences, or different classifications of generic key competences vis-à-vis the specialised substantial occupation-specific competences (Rychen and Sagalnik, 2001; EU-DG Education and Culture, 2007). In general, a distinction is made between a class of persistent, generic competences and a class of rapidly changing, specialised competences. The lifelong learning approach tends to draw on this distinction by proposing that the "general" components should be provided and acquired during initial ET, and the changing, "specialised" components should be left to continuing ET. This sounds very reasonable and it would indeed solve many of the coordination and matching problems if the proposed separation was practi$\mathrm{cal}$. This approach is consistent with a shift of VET to the tertiary level, and a transformation of schooling to the preparation for VET at the tertiary level. A number of distinguished researchers maintain that the VET sector might produce aggregate economic losses by providing less economically relevant competences as opposed to general education (Hanushek, 2006).

However, we must seriously take into account several important objections to this approach: (1) the practical implementation of the abstract distinction of general and specific competences is questionable; (2) the superiority of constructivist learning settings over traditional ones has so far not received sufficient empirical support ${ }^{4}$; (3) there are arguments suggesting that part of the younger population would only be motivated by concrete and practical settings; (4) a distinction can be made between practical (workplace) competences and theoretical (academic) competences, with both deemed necessary and to some extent mutually exclusive; and (5) some argue in favour of the necessity of the early acquisition of practical crafting skills (e.g., playing the violin or drawing), which are in turn countered by examples of traditional overspecialisation (e.g., a "real" electrician does only use a screw driver but never a screw wrench, whereas the opposite applies with a "real" mechanic).

It would appear that if we skip the qualification for specific occupations from secondary ET, we are able to bypass the problems of matching and coordination at the level where the task is most difficult. However, we should be aware that we might be losing substantial assets by adopting the tertiarisation

4. For instance, Allen and de Vries (2007) argue that the specialised substance competences would be necessary for the development of the general competences. 
approach. In addition, we must contend that the lifelong learning approach does not necessarily lead to the consequence of producing 'educated people lacking qualifications'. We can imagine various mixes of competences during the overall ET pipeline within a lifelong learning system, and such mixes are in fact prevalent in different ET systems.

The distribution of competences along people's ET careers is a serious problem about which we certainly do not know enough at the moment, and which is not seriously researched either. We must systematically compare the contested experiences of systems that have already taken the new tertiarisation path (e.g., Northern countries such as Finland or Sweden) to countries relying on the old upper secondary VET approach (e.g., countries in Continental Europe as well as the UK, which recently has developed upper secondary VET provision).

\subsubsection{Establishing new signalling systems spanning the education and the labour market} Taking up the argument of social structuration by institutionalisation, we have to recognise the information function of social structures such as qualifications or occupations - or their symbolic function, as argued by the cultural and neo-institutionalist approaches to organisation theory (Weick, 1976; Meyer and Rowan, 1977). In other words, if we consider those structures as meaningless, we also lack information - or even receive false or misleading information - about categories ("packages") of jobs and employees. Similarly, it has been argued that educational credentials serve as signals for "trainability", and therefore can be used in labour market transactions irrespective of their subject content.

With the rise of the market, the information problem has become a core issue of market failure in economic research. Relatedly, based on several studies about the tremendous diversity of VET systems in the 1980s and early 1990 s, the OECD championed the idea of creating a "common currency" in the labour market through the signals produced in ET (OECD, 1989). At the same time, the notion of competences, associated with the institutionalisation of qualification frameworks such as the NVQ-systems in the UK has spread throughout the Anglo-Saxon countries.

The proposal of a European Qualifications Framework (EQF) (EU, 2008) can be regarded as a novel attempt at establishing a signalling system, which would inform the various players about the competences inherent in employee qualifications. This political compromise model for the classification of ET outcomes has been confirmed at the European level as an instrument for providing transparency of the qualifications in the various member states. The procedures for the development of national qualification frameworks (NQFs) adopted by member states include a new attempt of taking stock of these qualifications structures; in some countries (e.g., Slovenia or the Czech Republic) the relation between ET and employment has been analysed and classified anew. Thus, the development of NQFs can be interpreted as a novel attempt at conceptualising and analysing the structural matching between ET and 
employment. These procedures constitute a kind of institution building that simultaneously provide structuration and information, even in the absence of a regulatory framework. In particular, countries with strong upper secondary VET systems - e.g., Germany or Austria - are using the transparency function to establish a new perception of the perceived value of their systems compared with other systems.

The explicit hierarchical framework of the EQF - which ranks HE qualifications over VET-qualifications - poses serious questions about the relation between the different sectors of ET supply. In particular, the relation between secondary and tertiary ET is a matter of debate. We mentioned before that upper secondary VET is perceived by its advocates as a functional equivalent to tertiary ET, including downplaying the central features of scientific knowledge creation and application (Lassnigg, 2006a). According to this view, craft competences should be classified at the same level as HE competences in a qualification framework, or in parallel frameworks in the case of a non-unified approach. The political processes do not explicitly address the substantial question, implicit in these debates, of whether HE education might constitute a different quality of competences as compared to secondary or postsecondary VET with respect to the proven mastering of scientific knowledge by $\mathrm{HE}$ graduation.

Two important aspects of the development of a new signalling device are neglected in pragmatic debates about the qualification frameworks: first, the specific quality of different types or kinds of signals in matching or coordination systems and processes; second, the evolutionary development of the distribution and rationing of access to forms of knowledge production in society. There exists a variety of dimensions in proposals for the classification of qualifications. In addition to the traditional distinction of qualification levels or specialisations and occupations, the concept of different kinds of competences has emerged. Moreover, the EQF compromise includes knowledge, skills, and competences based on different evolving interpretations. This suggests the development of a multi-dimensional space of matching according to different types of signals that fails to improve transparency. However, the specific roles of these different types of signals and their impact on the transaction structures and processes have seldom been explicitly discussed in the debates.

Two examples illustrate this concern. The first example concerns the different meanings of occupational categories and their use in different systems. Compare, for instance, the role of "employment-occupations" in traditional US industrial relations, which created inflexibility for employers by virtue of constituting particular employee rights, with the "training-occupations" in German or Austrian apprenticeship systems. The latter constitute supply-side signals, but not necessarily particular employment rights, as illustrated by the famous example of the bakers in the German automobile industry. If this distinction were neglected, and the German concept interpreted in the sense of the US category, this would imply a false notion of inflexibility within the apprenticeship system. 
As a second example we might point at the difference of VET qualifications producing "occupational categories", as opposed to HE qualifications generating "disciplines" that are defined independently and operate using a different logic from the supply side occupational or professional development. From an abstract point of view of the use of information in coordination, the independent information provided by relatively stable categories might be more effective than the formulation of qualifications in terms of occupations that interact strongly with the dynamics on the demand side. The factual supply-side definition of training-occupations might be thought to have similar strengths. However, it might also include a type of "realistic fallacy" towards employment-occupations because their labelling as occupations suggest that they are extracted from real employment instead of being constructed in VET. Competencies as a specific type of signals might represent similar strengths. When used coherently, they could be formulated independently from either the supply and demand side, and consequently used by both sides as an exchange medium that bridges the gap between the ET market and the labour market. The distinction between the different dimensions in complex matching and coordination systems is more important in this perspective than the tendency for collusion of these different dimensions prevalent in ongoing debates.

\section{The Contested Role of Policy: Demands vs. Potentials?}

\subsection{Conflicting demands}

Demands and expectations from policy represent a key issue in the matching and anticipation of VET and employment. As long as VET is provided publicly, the question remains whether its provision can meet the demands of clients. There are many potential clients whose demands and interests only partially overlap: both young and older people want to enlist in training courses; employers need employees with sufficient competences; providers (teachers or trainers) need an income; policy makers and interest organisations want satisfied clients, etc. At an abstract level, those interests may align, but in practice they entail several differences and conflicts.

We have already pointed at the conflicts between the supply and demand side in the labour market, and at the diverging positions of parents and young people. Providers and teachers often have strong vested interests, and are powerfully organised to enforce these. Policy makers eager to win elections have to decide how to deal with these conflicting positions and interests, which to address and which to turn down.

\subsection{Expectations from theories and practical approaches}

The theoretical approaches surveyed above entail very different expectations and advice about the role of policy makers regarding the relation between ET and employment, which can be briefly summarised as follows: 
1) Systems theory sees the political system as a system operating with its own logic, and would not expect it to contribute to the coordination of two other subsystems.

2) Innovation theory puts strong demands on the political system by emphasising that radical innovation does not incrementally evolve from market behaviour, and instead has to be put in place by a complex framework of innovation policy.

3) Theories of institutional change mostly analyse emergent processes in society, and consequently do not have a systematic perspective on how these changes might be influenced by policy makers; however, implicit contentions appear to favour self-organising processes over the political system.

4) Theories of the market generate mixed expectations about the role of policy. They typically expect the provision of appropriate framework conditions for the market to function properly, but there is wide disagreement about which framework conditions are appropriate for ET and employment. The influential neoliberal paradigm is suspicious about what public institutions are able to deliver in VET, pleading for market provision and strong evaluation of everything carried out by public institutions. By contrast, others have pointed at various sources of market failure and insist on public corrective measures.

5) Theories of learning and competences pay scant attention to framework issues of who should be responsible for the creation of adequate learning conditions.

The practical solutions presented above vary about their expectations to the political system: Forecasting/planning and lifelong learning entail strong requirements for systematic policy action. Marketisation/deregulation and signalling address the framework conditions which have to be created by the political system. Finally, the ET supply ideal remains relatively indifferent to the political system, but can surely profit from its support.

\subsection{Relationships between theories and practical solutions}

The next step of the analysis is to ask how to ensure the compatibility of practical solutions and theoretical approaches. Table 1 displays systematic a-priori relations between the theoretical approaches as sketched above and the set of practical solutions. We can identify an interesting pattern showing distinct overall relations for each of these practices:

1) Forecasting and planning displays negative relations to three approaches and no positive relation;

2) The two practices of lifelong learning and signalling are positively related to some approaches, and do not display negative relations;

3) Marketisation and ET supply ideals demonstrate the highest degree of variability in their relations to a number of different theoretical approaches. 
Table 1. Systematic relations between theoretical approaches and practical solutions

\begin{tabular}{llllll}
\hline & $\begin{array}{l}\text { Forecasting } \\
\text { and planning }\end{array}$ & $\begin{array}{l}\text { Marketisation } \\
\text { and deregulation }\end{array}$ & $\begin{array}{l}\text { ET supply } \\
\text { ideal }\end{array}$ & $\begin{array}{l}\text { Lifelong } \\
\text { learning }\end{array}$ & Signalling \\
\hline $\begin{array}{l}\text { Systems } \\
\text { theory }\end{array}$ & - & - & + & & + \\
$\begin{array}{l}\text { Innovation } \\
\text { theory }\end{array}$ & & & & & + \\
$\begin{array}{l}\text { Institutional } \\
\text { change }\end{array}$ & - & - & + & \\
$\begin{array}{l}\text { Labour market } \\
\text { theory }\end{array}$ & - & & & & + \\
$\begin{array}{l}\text { Learning and } \\
\text { competences }\end{array}$ & & + & - & & + \\
\hline
\end{tabular}

Legend: $(+)=$ practice does positively comply with the approach; $(-)=$ practice is contradictory to the approach; $(\sim)$ = practice is compatible with approach; ()$=$ practice is not defined in relation to the approach.

Source: Own compilation.

If we accord a degree of predictive power to the different theories, this pattern suggests that practices that display negative or contradictory relations will be more problematic to implement than those that only show positive relations.

\section{The Austrian Experience of Matching and Coordination}

Since 2004 a series of research projects have analysed in some depth a number of topics concerning the mechanisms of anticipation and matching in Austrian VET (Lassnigg and Markowitsch, 2005; Lassnigg, 2006b, Lassnigg and Vogtenhuber, 2007; NQF-Consortium, 2007). These include (1) the experience with quantitative forecasting and the utilisation of forecasting results, (2) the structure and practice of communication flows among the different categories of actors in the development of new VET programmes in schooling, apprenticeship, tertiary polytechnics (FHs) and continuing VET, (3) qualitative mechanisms of skills demand anticipation in selected areas (e.g., new curricula in VET colleges, new apprenticeship programmes, and labour market training in a particular "good practice" region), (4) the use of data and indicators about matching, (5) the development of a regional system of anticipation of the demand for skills and competences, (6) monitoring the empirical relation between ET and employment based on the Labour Force Survey (LFS) data, (7) the preparation of a consultation document for the development of an Austrian National Qualification Frame (NQF), including the analysis of the outcome orientation of Austrian VET. These studies offer a good overview of the practices as well as the views adopted by the different actors in the system. 


\subsection{Assessment in terms of theories}

\subsubsection{The Austrian information paradox about matching and coordination}

Looking at the Austrian case from the point of view of different theoretical approaches indicates we cannot rely on current rigorous research. However, we can combine what we know about the functioning of the system and make some generalisations. A stylised picture of the Austrian matching and anticipation system includes the following main traits (Lassnigg, 2004):

1) The VET system is very specialised in terms of qualifications, comprising two main sectors of about equal size but organised differently. On the one hand, we find a supply-driven full-time schooling system with two main layers. On the other hand, we find a partially market-driven, strongly regulated apprenticeship system.

2) Several distinct mechanisms of coordination and anticipation persist, relying primarily on the practical knowledge of the actors in these systems. The main actors are situated on the supply side - in the school system, in the departments of the federal ministry, and in apprenticeship mainly in training enterprises - but supported by the social partners.

3) An overall coordinating device is lacking, which means the sub-systems compete with each other in various ways; nor can we find an overall monitoring system of their development. There exist only scant statistics about enrolment in schools and in apprenticeship, while statistics about financing and about the balance on the apprenticeship market are available at aggregate levels, but unrelated to the former. Regular information about issues such as the employment destination of specialised VET graduates or the financial contributions of training enterprises to apprenticeship is simply not available, and not even called for.

4) The relationship between ET supply and employment at the level of training specialisations has not been observed regularly. Generalised knowledge is not available about the jobs in which the specialised supply of ET is employed. Generalised knowledge about specific aspects, such as working conditions, income, knowledge usage, skills and competences, is also lacking.

5) The public employment service provides several information sources, including forecasting studies, qualitative descriptions and a system of observing qualification needs. However, the latter does not include information about formal ET qualifications, but instead uses a special decontextualised classification of tasks and competences constructed independently from formal ET.

In terms of matching and coordination, this constitutes a paradoxical structure. On the one hand, most actors are very confident about the importance and economic significance of specialised supply of VET qualifications from school and apprenticeship. On the other hand, these actors do not have basic information to empirically test their confidence. Until recently, not even a gen- 
eralised statistical classification about the specialisations of VET programmes was available.

Cross-sectional statistical information that includes ET specialisations and information about employment has only been collected every ten years in the regular population census, and more detailed statistical information has only become available from this source with a further time lag of six years. For instance, matching information about VET and employment collected in 1991 was not published until 1997 or 1998, delaying usage of this information for a decade. There have been many small studies about skills utilisation in certain sectors, but in many cases these remain unpublished and without recognition in the community, and even where published lack the necessary statistical corroboration or testing. This means the building of a cumulative knowledge base has not yet taken place.

A telling example illustrating this lack of information is the ongoing debate about the small supply of tertiary graduates in Austria. Every year since the OECD published its comparative statistics in "Education at a Glance", this problem is highlighted and stirs a debate within the Austrian policy and expert communities how to evaluate this small rate of tertiary graduates in the population. One prominent argument maintains upper level secondary VET colleges are equivalent to tertiary education, even if strictly speaking they are not tertiary institutions. Another argument states that certain specialised VET qualifications are more in demand and more important for the economy than tertiary qualifications. The "facts" in this debate are always based on anecdotal "evidence" or "practical knowledge". Interestingly, conventional empirical indicators - e.g., rates of return or employment/unemployment rates - fail to reinforce that contention. The contrary is not evident from the available information either. However, that matter is not really a "hot issue", in which evidence is sought by the actors - rather they seem content relying on seemingly proven "facts" that are able to reinforce various contentions or ideologies.

\subsubsection{Explanations of the paradox by the theoretical approaches}

Against the background of the knowledge society, this open and unrecognised knowledge gap should be taken as a significant explanandum. How does this phenomenon fit within the theoretical propositions outlined above?

1) Systems theory can easily integrate the paradox through the hypothesis of the autopoiesis of subsystems: ET and employment are based on different communication codes, and their coupling has to be provided by additional mechanisms based on assets each system provides for the other. As long as it is content with its development, the ET system does not require stronger evidence from other systems.

2) Innovation theory looks for barriers to innovation, typically based in the institutional structures of the existing innovation regime. Research in this approach offers consistent explanations of the paradox in terms of a short- 
sighted "institutional match" rapidly leading to a long-term "institutional mismatch" since the system systematically prefers incremental innovation over radical innovation; yet any move towards the technology frontier would require radical innovation (Lassnigg, 2006a).

3) Similarly, the hypothesis about modernisation points at institutional inertia or sclerosis because institutional actors are locked in the old structures of qualifications and occupations that would have been undermined by changes in society.

4) Traditional labour market theory views the system as being strongly regulated and supply-oriented, and requiring deregulation. The model of occupational labour markets seems to fit segmentation theory, and maybe even the old picture of "balkanisation". The theorem of the problematic interaction between the education market and the labour market corresponds to this situation, and appears to explain the separation as well as the periodic debates about "mismatch".

5) The new theories of learning and competences clearly challenge the existing structure. Thus, they can be used as a "ferment" by actors trying to change the system. However, we find competing perspectives on the relation between "old" and "new" paradigms: they can be interpreted either as a complementarity hypothesis, suggesting old occupational competences merge with new ones, or as a substitution hypothesis, maintaining instead that new competences crowd out the old occupational competences because of time and capacity constraints.

In sum, we can see that the paradox can be integrated to a varying extent in each of the different theoretical approaches. Overall, these approaches do not perceive matching and coordination of ET and employment as an objective that can be practically achieved without problems or contradictions. Instead, they believe technical solutions will not work.

\subsection{Practical solutions taken and contested in the Austrian system}

A comprehensive policy in the area of matching and coordination of ET and employment was never developed in Austria. But several piecemeal attempts have taken place, which can be summarised as follows:

1) Forecasting is not systematically employed for the development of VET supply. While some studies have been commissioned by the Public Employment Service (AMS), these have not been used by practicioners; for the most part, the ET authorities have not been aware about the existence of those studies. In addition, forecasting has been actively denounced as useless by several actors. Nevertheless, some regional actors and the AMS continue to commission conventional forecasting studies concerning ET demand, which are still neglected and even opposed by the main actors. The supply side is seldom included in those studies. 
2) The market plays some role in continuing VET (CVET) and in apprenticeship, but is strongly constrained by institutional structures and regulations. In CVET the share of labour market training for the unemployed provided by AMS is about a third, which means many employees have to become unemployed before they receive training. The main providers of CVET are the social partners or non-profit organisations and enterprise training, but the market is affected by strong information problems and a lack of transparency. In relation to apprenticeship, the market is shaped by an occupational structure that is part of the economic regulation of the trade structures and does not follow training imperatives. Compulsory part-time school for apprentices plays only a subsidiary role, with strong coordination problems affecting the relation to enterprise. Training decisions by enterprises typically follow traditional customs rather than economic rationality, and overall apprenticeship training is expensive and estimated to contain net costs for enterprises.

3) Austrian VET is largely dominated by supply-side decisions. In VET schooling, it is regarded as a strength that public providers put the longterm qualification interests of young people and the sustainable needs of employment at the centre of this system (Lassnigg and Mayer, 2001; Steiner, 2005). The needs of the demand side are increasingly accommodated through the establishment of communication mechanisms: for instance, systematic workshops for curriculum development that include employers or evaluations of the uses of existing curricula in employment. Demand issues are brought more strongly into perspective in apprenticeship and the FH sector, but when we analyse these mechanisms in more detail, we also detect a strong 'hidden' supply-side orientation. First, for more than a decade the market has failed to provide sufficient apprenticeship places to satisfy the training demand by young people. However, the response is not to scrutinise the structure of incentives, which would be a demand-side market solution (Wolter, Mühlemann and Schweri, 2003), but rather to provide subsidies to stimulate new demand, which seems to produce substantial windfall effects by subsidizing enterprises who would have taken on apprentices anyway. Second, in the FH sector a test for the demand for specific qualifications is required in the accreditation process of new programmes. However, as systematic monitoring of the overall development of demand is lacking, such testing is only carried out (mostly through surveys of enterprises) for newly planned programmes that might maximally enrol a couple of students. The results cannot withstand rigorous statistical testing. Moreover, the procedure is driven by the supply organisations who decide to apply for such a new programme and thus determine whether such a test is run or not; consequently, demand that is not considered by a supplier is not tested (Lassnigg et al., 2003).

4) Lifelong learning amounts to a comparatively weak link in the system. While participation is at EU average, for many years debates about the 
development of a national strategy have taken place, and more recently the social partners have called for stronger action in this area. Although steps towards a consultation process were initiated, so far a systematic strategy for a new division of labour between initial VET and continuing VET is not envisaged - with the exception of a few prophets "calling in the desert" (Biffl, 2007). ${ }^{5}$ A frequently cited argument in the Austrian VET community holds that high participation in continuing VET is only necessary in ("second best") systems that do not include a strong upper secondary VET provision.

5) Concerning signalling we observe different contentions. In the recent debates about the development of an Austrian NQF, a dominant position maintains that Austria employs a framework based on traditional qualifications, and that the NQF should mainly be used as a "transparency instrument" to demonstrate the superior position of Austrian VET in light of recurrent criticism about its low tertiary supply. Thus, it is generally held that, at a minimum, the NQF improves signalling at the transnational level. Besides, some voices criticise the transparency of the system for being insufficient, insisting both on more transparency and better pathways for following through the system through further development of the NQF. There are strong voices in place insisting on the priority of strengthening learning outcomes through the NQF, mainly envisaged as output standards in VET schooling. However, so far not many conceptual or material resources have been devoted to this priority.

In sum, it appears that the Austrian ET system functions without formal methods of matching and coordination. Little objective information is available about the degree to which it functions well, however: many of the available comparative indicators - that give a crude picture - are positioning Austria on the average level. Some indicators are quite positive:, e.g., youth unemployment is low. Policy action has mainly confirmed the status-quo, but disputes about quality remain. However, a strong inclination to improve formal knowledge about the functioning of the system, which we would expect in a knowledge society, is still lacking. Instead, the archaic practice of faith healing seems to prevail.

\section{Conclusions: Lessons and Proposals for Further Development}

Combining the general reflections and the analysis of the Austrian practice we can offer several generalisations, leading to further questions.

First, the theoretical scope of issues pertaining to matching and anticipation is quite wide and includes a number of different and even contradictory conclu-

5. After almost 15 years a strategic document has been published by the Austrian government, that provides the various policy actors with comprehensive guidelines, but does not commit to any strong political action (see Republik Österreich 2011). 
sions. More research is needed, but we should keep in mind that these theoretical contradictions are of a conceptual rather than an empirical nature, and we should not expect them to be resolved by conducting more empirical research.

Second, the practical solutions available in these discourses, as well as in empirical practice, are either not well-founded in theory or else strongly tied to specific theories that are not accepted by all actors. In general, more open and theoretically invariant approaches might be more easy to implement than theoretically demanding practices. This rules out the approaches of forecasting/ planning, marketisation/deregulation, and the ET supply ideal, and supports lifelong learning and signalling.

Third, when seeking solutions for matching and anticipation, the overall relationship between the political system and the matching problems between ET and employment as distinct subsystems should be more thoroughly taken into account. If too strong demands are placed on the political system, it might be unable to cope with them on substantiated grounds and not merely because of some contingent deficiency or unwillingness. This constraint rules out forecasting/planning and lifelong learning, and supports marketisation/ deregulation, the ET supply ideal, as well as signalling; with the latter being the only approach to receive two "positive hits".

Fourth, the strength and the variety of the Austrian VET system and practice offers interesting insights that are useful to a broader perspective. Of course, the Austrian experience does not show all possible problems and solutions, but nevertheless illustrates a broad range. A detailed analysis might therefore generate further insights of general significance. In particular, we can learn a number of lessons from the functioning of the Austrian system, which can be related to the forms of theoretical and practical reasoning brought forward in this paper:

1) The Austrian system has strongly institutionalised upper secondary VET as a diversified system, providing recognised qualifications for more than $70 \%$ of a cohort - a proportion that is among the highest in the world. HE only plays a comparatively minor role in the provision of qualifications.

2) Regarding theoretical approaches, both systems theory's predictions about distinct logics of development of ET and employment, and innovation and modernisation theory's predictions concerning weaknesses inherent to innovation and the strength of institutional inertia, fit to the basic development of the Austrian system and Austrian policy. The coupling of ET and employment is governed by established institutional habits, and the market plays only a minor and contested role. By contrast, new theories of learning and competences have only received partial acceptance, and in particular are discarded by the established structures and practices.

3) In terms of the practical approaches towards matching, the ET supply ideal remains the predominant mode of functioning. More recently it has been supplemented to some extent with market mechanisms. However, so far the main actors have not accepted forecasting and planning or the market 
approach as genuine alternatives. The use of forecasting is contested by its moderate supporters in the Public Employment Service and ignored by the main actors on the ET supply side. The use of the market is to some extent called for by employers' representatives, but rejected by the employees' side and by ET advocates. Finally, the signalling approach receives only marginal support as a transparency device, and there exists considerable consensus that an operative role of signalling for matching (e.g., by occupying a regulatory role) should not be envisaged.

4) A strong impetus for modernising the system in the direction of support for innovation emerged in the second half of the 1980s, chiefly because of a perception of major structural problems in the economy. The subsequent opening up of the Central and Eastern European Countries (CEECs) has markedly postponed this debate because of a successful expansion along traditional trajectories in this area. The available empirical evidence about the strengths and weaknesses of the innovation system is mixed, although rigorous accounts are lacking: the economy is successful and social disparities are not very marked, the economy maintains a traditional structure, and innovation is occurring mainly in traditional fields. Despite the low supply of tertiary graduates, particularly in the sciences and technology, there are no visible and unequivocal signs of a strong undersupply of these qualifications. The same appears to be the case concerning continuing ET: despite moderate participation, clear signs of undersupply do not pertain.

5) Taken together, the predominantly supply-driven system is widely accepted by the main actors, and appears to function well without the existence of designated mechanisms of matching and coordination.

Fifth, systems theory and the market approach have the largest explanatory power by virtue of being able to discriminate (albeit in opposite directions) between the practical solutions. Innovation theory and theories of learning and competences commonly go in the same direction by being positively related to the ET supply ideal and to lifelong learning, whereas theories of institutional change are the most pessimistic approaches and show only a negative relation to each of the practical solutions. The latter is not surprising since they regard the inability of the institutional structures to cope with emergent processes of change as a key problem of societal development.

Sixth, when we focus on the relation between theoretical approaches from the perspective of practical solutions, as displayed in table 1, we also obtain some interesting insights. Lifelong learning and signalling are positively related to particular approaches, and do not have negative predictions from any. The ET supply ideal practice is problematic from the point of view of the market approach. However, it receives positive support from the other theories and displays the largest number of positive signs in the table 1 . In terms of our theoretical expectations, this latter practice seems to function better than its reputation signals. 
Finally, what conclusions can we draw from the previous reflections for theory, practice and policy?

Theory. It should be made clear at the outset that matching and coordinating ET and employment is by no means a simple task that "has only to be done" by responsible actors, as is frequently called for at the political level. Instead, it is a problem that involves deep theoretical reasoning, and to some extent goes beyond the knowledge covered by the conventional theories. Systems theory, which already struggles with the understanding of single systems, perceives the interrelation of two or three systems as a very demanding task. For the theory of the market too the interrelation with institutions constitutes a demanding task. Theories of institutionalism, in turn, demonstrate the limits of institutions and their inertia, rather than explaining institutions' potential for coping with change. It would appear much has still to be done to understand these interrelations at a theoretical level.

What is required to understand these problems are theories that span action and structure, and bridge individual and collective action. One candidate is the theory of transitional labour markets (TLM), which has conceptualised the relation between action, structures, and policy (Lassnigg et al., 2007). Another candidate is the triple helix hypothesis that tries to understand the relation between three systems in the field of innovation and technology. From the perspective of policy making, governance theory tries to understand the complex relationships of various actors and their relation with structures in certain policy fields. Finally, an approach that sets off from the analysis of distinct coordination mechanisms at a meso-level might also contribute to the understanding of the problem. However, similar to systems theory, this coordination approach is also very much related to the understanding of certain mechanisms - bureaucracy, the market, associations, and networks - and is also overburdened by the interaction of these different mechanisms, which is typically the case concerning matching and coordination of ET and employment. An important strand within the governance approach is policy learning, which has been analysed using the "open method of coordination" in relation to multilevel and soft law governance in the EU. We can apply policy learning to the matching problem, and use the key concepts of this approach to structure the problem.

From the literature we can infer two types of operationalisable and observable policy learning channels. To begin with, Zeitlin $(2005,2006)$ distinguishes three mechanisms of policy learning:

1) Heuristics refers to the establishment and use of new concepts to describe and understand certain policy areas, leading to some degree of new rhetoric.

2) Capacity building entails the establishment of new mechanisms or instruments of knowledge production in certain policy areas (e.g., new systems of indicators or new data based on monitoring systems), resulting in new information that might establish competing views to prevailing policies. 
3) Maieutic procedures are new mechanisms for reflection about certain policies (e.g., task forces or reporting procedures), which might lead to altered or new policy practices.

Based on his analysis of British economic policy changes, Peter Hall (1993) defined a second type of policy learning channels following the well-known forms of learning at increasingly complex levels of change:

$1^{\text {st }}$-order learning comprises learning that is focused on the experience with different policy levels; this kind of learning, if it occurs, is very much incremental learning based on past experience, and aims to expand or reduce established policies without adding substantive new elements.

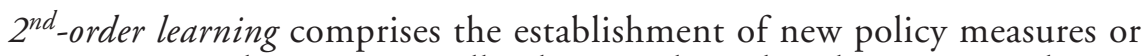
instruments within given overall policy paradigms based on given goals; it is analogous to product-innovation, based on a combination of past experience and specialised new information.

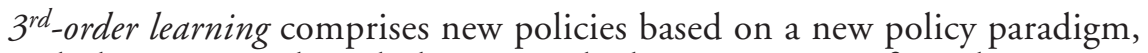
including new goals and objectives; the basic structure of a policy is now changed, which is analogous to radical innovation based on new information.

Practice. If the theoretical understanding of our problem remains open, how should we deal with the practical task or challenge of matching and coordination? Looking at the problem from the point of view of governance and policy learning, we can infer that to develop matching and coordination requires finding a proper understanding of the problem (heuristics), developing information and monitoring (capacity building), and building mechanisms to reflect on "good practice" (maieutic mechanisms). Related to each of these mechanisms we can develop $1^{\text {st }}$ order, $2^{\text {nd }}$ order, and $3^{\text {rd }}$ order learning. A proper understanding of the problem is a key issue, as the constructivist nature of the problem is often overlooked and permeated by various types of "realistic fallacies" that envisage demand as mere "facts". The image of "early recognition" can be taken as a paradigm case of a realistic fallacy, for it portrays a real change similar to the spread of cancer in biology. The contrasting image would be a form of "institutional shaping" of demand that begins with the construction of the dimensions and categories of qualifications, competences, occupations, professions, and so on, followed by the establishment of mechanisms and models of foresight and forecasting, and their contribution to knowledge production.

Policy. From this point of view, matching and coordination might include a policy vision that is able to step into the gaps of uncertainty and give the system a strategic direction. Alternatively, it might adopt the Austrian solution of,incremental and uncoordinated development of the various parts of the system. Several mechanisms and sets of local equilibria and disequilibria, 
including various sources of flexibility, take over the role of coordinating an uncoordinated system. This appears to work reasonably well, as long as no radical changes are necessary - but what does "necessary" mean in the constructivist paradigm?

\section{Literature}

Allen J. and DE VRIES R. (2007). "Determinants of Skill Mismatches". In: LASSNigG, L.; BurzlafF, H.; Davia RodrigueZ, M.A. and Lassen, M. (Eds.), Lifelong Learning:Building Bridges Through Transitional Labour Markets. Apeldoorn Antwerpen: Het Spinhuis, 45-63.

Barr, N. (2001). The Welfare State as Piggy Bank. Oxford: Oxford University Press.

BECK U. (1992). Risk Society: Towards a New Modernity. London: Sage.

Berryman, S.E. and Bailey, T.R. (1992). The Double Helix of Education and the Economy. New York, Teachers College (Columbia), Institute on Education and the Economy.

BIFFL, G. (2007). "Erwachsenenbildung - Schlüssel für die Erhaltung der Wettbewerbsfähigkeit Österreichs". Online Magazin Erwachsenenbildung, 2 (Oct.). <http:// www.erwachsenenbildung.at/magazin/meb07-2.pdf> [Query: 2011-07-27].

BlaUG, M. (1976). "The Empirical Status of Human Capital Theory: A Slightly Jaundiced Survey". Journal of Economic Literature, 14 (3), 827-855.

BoOTH, A.L. and SNOWER, D.J. (Eds.) (1996). Acquiring skills: Market Failures, Their Symptoms and Policy Responses. Cambridge: Cambridge University Press.

EU-EUROPEAN UNION (2008). Recommendation of the European Parliament and of the Council on the establishment of the European Qualifications Framework for lifelong learning. EDUC 178 SOC 399 CODEC 1134. 29 January 2008. Brussels: European Parliament/Council. <http://ec.europa.eu/education/policies/educ/eqf/ rec08_en.pdf> [Query: 2011-07-27].

EU-DG EdUCATION AND CULTURe (2007) Key Competences for Lifelong Learning European Reference Framework. Luxembourg: Office for Official Publications of the European Communities.

EU-DG EMPLOYMENT AND SOCiAl AfFairs (2002). Structural changes in the European labour markets. Ch.2 in Employment in Europe (EIE) 2002. Luxembourg: Office for Official Publications of the European Communities, 47-78. <http://www.ispesl. it/dsl/dsl_repository/Sch24PDF08Marzo06/Sch24employment_in_europe2002. pdf> [Query: 2011-07-27]

EU-DG Employment, Social Affairs and Equal Opportunities (2006). Human Capital, Technology and Growth in the EU Member States. Ch. 4 in Employment in Europe (EIE) 2006: Luxembourg: Office for Official Publications of the European Communities, 173-201. Internet<http://digitalcommons.ilr.cornell.edu/cgi/viewcontent.cgi?article=1031\&context=intl> [Query: 2011-07-27] .

GruBB, W.N. (2002). "Who am I: The inadequacy of career information in the information age". Paper commissioned jointly by the European Commission and the OECD. Paris: OECD. <http://www.oecd.org/dataoecd/32/35/1954678.pdf> [Query: 2011-07-27].

Hall, P.A. (1993). "Policy Paradigms, Social Learning, and the State: The Case of Economic Policy Making in Britain”. Comparative Politics 25 (4), 275-96.

HanusheK, E.A. (2006). "Alternative School Policies and the Benefits of General Cognitive Skills". Economics of Education Review 25 (4), 447-462. 
HAYWARD, G. (2004). "Vocationalism and the Decline of Vocational Learning in England". Berufs- und Wirtschaftspädagogik - online bwp@ Issue No. 7 (December). Vocational and Business Education and Training in Europe: Qualifications and the World of Work. <http://www.bwpat.de/7eu/hayward_uk_bwpat7.pdf> [Query: 2011-07-27].

Heikkinen, A. (1997). "Vocational Education as a 'Life Project'? Reflections from the Case of Finland". Journal of European Industrial Training, 21 (6-7), 213-219.

Jacobs, B. and van der Ploeg, F. (2005). "Guide to Reform of Higher Education: A European Perspective”. CEPR Discussion Paper No. 5327. London: Centre for Economic Policy Research.

LASSNIGG, L. (2004). "To match or mismatch? The Austrian VET system on struggle with diverse and changing demand". Berufs- und Wirtschaftspädagogik - online bwp@ Issue No. 7 (December). Vocational and Business Education and Training in Europe: Qualifications and the World of Work. <http://www.bwpat.de/7eu/ lassnigg_at_bwpat7.pdf> [Query: 2011-07-27].

LASSNIGG, L. (2005) "Indikatoren zur Erfassung der Qualität des Zusammenspiels von Angebot und Nachfrage in der Berufsbildung". In: Lassnigg, L. and Markowitsch, J. (Eds.), Qualität durch Vorausschau. Innsbruck: Studienverlag, 179-228.

LASSNIGG, L. (2006a). "Social Organization of Knowledge in VET: Challenges for Schooling and Apprenticeship in Austria”. In: Mjelde, L. and Daly, R. (Eds.), Working Knowledge in a Globalizing World. Bern: Peter Lang, 267-291.

LASSNIGG, L. (2006b). "Approaches for the Anticipation of Skill Needs in the 'Transitional Labour Market' Perspective: The Austrian Experience”. In: WZBDiscussion Paper SP I 2006-105. Berlin: Wissenschaftszentrum Berlin fuer Sozialforschung (WZB). <http://skylla.wz-berlin.de/pdf/2006/i06-105.pdf> [Query: 2011-07-27].

LASSNIGG, L. and MARKOWITSCH, J. (Eds.) (2005). Qualität durch Vorausschau. Antizipationsmechanismen und Qualitätssicherung in der österreichischen Berufsbildung. Innsbruck: Studienverlag.

LASSNigG, L. and MAYER, K. (2001). "Definition and Selection of Key Competencies in Austria”. Country Report on the BFS-OECD Project DeSeCo. IHS Sociological Series No. 53. Vienna: Institute for Advanced Studies. <http://www.ihs.ac.at/ publications/soc/rs53.pdf> [Query: 2011-07-27].

LASSNIGG, L. et al. (2003). "Review des Auf- und Ausbaues des Fachhochschulsektors". IHS Research Report. Vienna: Institute for Advanced Studies. <http://www.equi. at/dateien/fh-review.pdf> [Query: 2011-07-27].

Luhmann, N. and ScHOrR, K.-E. (2000). Problems of Reflection in the System of Education. European Studies in Education. Münster: Waxmann.

Lundvall, B.-A. and Borrás, S. (1998). The Globalising Learning Economy: Implications for Innovation Policy. Luxembourg: Office for Official Publications of the European Communities.

MEYER, J.W. and Rowan, B. (1977). "Institutional Organizations: Formal Structure as Myth and Ceremony". American Journal of Sociology 83 (2), 340-63.

Middleton, J.; Ziderman, A. and van Adams, A. (1993). Skills for Productivity. Oxford: Oxford University Press.

NeugART, M. and SCHÖMAnN, K. (Eds.) (2002). Forecasting Labour Markets in OECD Countries. Measuring and Tackling Mismatches. Cheltenham: Edward Elgar.

NiEUWENHUIS, L.F.M. (2004). "Making the Future: Dealing with Uncertainty in Developing and Delivering Vocational Education and Training". In: SCHMIDT, S.L.; STRIETSKAIlina, O.; Tessaring, M. and DwOrschaK, B. (Eds.), Identifying Skill Needs for the Future. From Research to Policy and Practice. Luxembourg: Office for Official Publica- 
tions of the European Communities. Cedefop Reference Series 52, 64-75. [Internet: <http://www.cedefop.europa.eu/EN/Files/3037_en.pdf> [Query: 2011-07-27].

NQF-CONSORTIUM (2007) Entwicklung eines Nationalen Qualifikationsrahmens für Österreich - Vertiefende Analysen. Research report commissioned by the Austrian Ministry of Science, Research and Culture. Vienna: Institute for Advanced Studies. <http:// www.equi.at/dateien/NQR-Vertiefende-Studien-Endb.pdf> [Query: 2011-07-27].

OECD (1989). Pathways for Learning: Education and Training from 16 to 19. Paris: OECD.

Planas, J.; Giret, J.-F.; Sala, G. and Vincens, J. (2002). “The Skills Market: Dynamics and Regulation". In: Descy, P. and Tessaring, M. (Eds.), Training in Europe. Second Report on Vocational Training Research in Europe 2000: Background Report. Vol. II. Cedefop Reference Series. Luxembourg: Office for Official Publications of the European Communities, 313-381.

Rauner, F. and Heinemann, L. (2008). "Occupational Commitment and Vocational Identity". Paper at the Conference of the International Network on Innovative Apprenticeship "Situated Competence Development Through Innovative Apprenticeships”. Vienna, 1-2 February 2008. <http:/www.oeibf.at/db/calimero/tools/ proxy.php?id=12774> [Query: 2011-07-27].

RePUbliK ÖsterReICH (2011). Strategie zum lebensbegleitenden Lernen in Österreich. Vienna: Austrian Government. <http://www.bmukk.gv.at/medienpool/20916/ lllarbeitspapier_ebook_gross.pdf> [Query: 2011-07-27].

Rychen, D.S. and SAgalniK, L.H. (Eds.) (2001). Defining and Selecting Key Competences. Seattle: Hogrefe \& Huber.

SENGENBERGER, W. (1987). Struktur und Funktionsweise von Arbeitsmärkten: Die Bundesrepublik Deutschland im internationalen Vergleich. Frankfurt/New York: Campus.

SENNETT, R. (1998). The Corrosion of Character: The Transformation of Work in Modern Capitalism. London: Norton.

STEINER, M. (2005) "Qualitativ-praktische Aspekte der Antizipation”. In: LASSNIGG, L. and MARKOWITSCH, J. (Eds.), Qualität durch Vorausschau. Innsbruck: Studienverlag, 123-178.

WEICK, K.E. (1976). "Educational Organizations as Loosely Coupled Systems". Administrative Science Quarterly, 21 (1), 1-19.

WiLSON, R.A. (2007). "European Skills for the 21st Century". Presentation at AGORA Thessaloniki XXVI Conference "Building a European VET Area", 26-27 April 2007. <http:/www.trainingvillage.gr/etv/Upload/Projects_Networks/Skillsnet/ Publications/Wilson-European_skills_for_the_21st_century.pdf> [Query: 201107-27].

Wolter, S.C.; Mühlemann, S. and Schweri, J. (2003). "Why Some Firms Train Apprentices and Many Others Do Not”. IZA Discussion Paper No. 916. Bonn: Institute for the Study of Labor (IZA).

Zeituin, J. (2005). "Social Europe and Experimentalist Governance: Towards a New Constitutional Compromise?”. European Governance Papers (EUROGOV) No.C05-04. <http://www.connex-network.org/eurogov/pdf/egp-connex-C-05-04.pdf>.

Zeituin, J. (2006). "When Do Policy Innovations Spread? Lessons for Advocates of Lesson-drawing". Harvard Law Review, 119, 1466-1487. <http://eucenter.wisc.edu/ OMC/New\%20OMC\%20links/policy_innovations.pdf> [Query: 2011-07-27].

Zukersteinova, A. and Strietska-Ilina, O. (Eds.) (2007). Towards European Skill Needs Forecasting. Cedefop Panorama Series 137. Luxembourg: Office for Official Publications of the European Communities. 


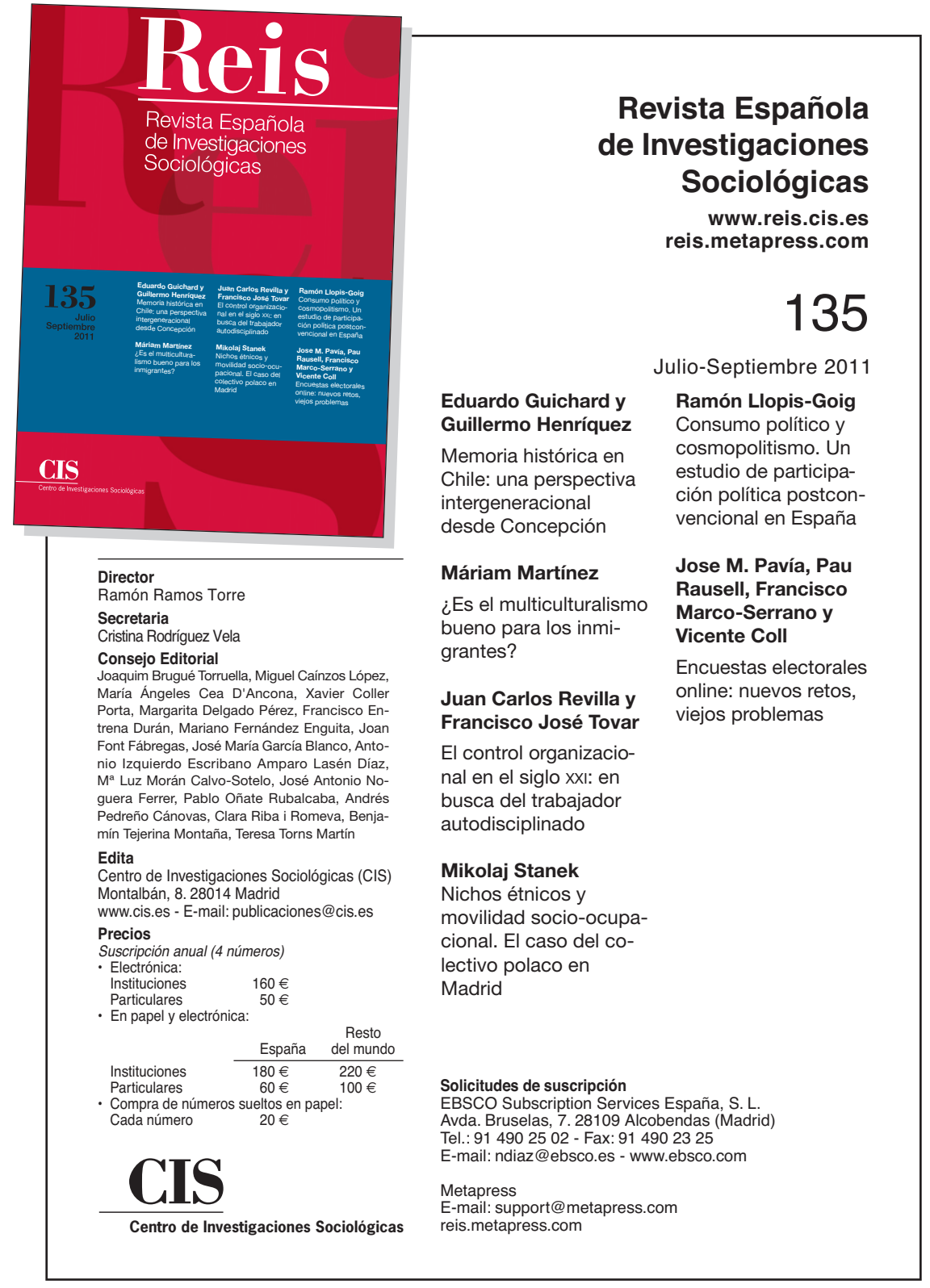

